\title{
EFFECT OF SELF - CARE LEARNING PACKAGE ON THE QUALITY OF LIFE FOR PATIENT WITH URINARY DIVERSION \\ ${ }^{1}$ Mona Mohammed Ibrahim, ${ }^{2}$ Amany Mohamed Shebl, ${ }^{3}$ Hassan Abol- Enein, ${ }^{4}$ Abeer Yahia Mahdy \\ ${ }^{1}$ Medical Surgical Nursing, Faculty of Nursing, Aswan University \\ ${ }^{2}$ Medical Surgical Nursing, Faculty of Nursing, Mansoura University \\ ${ }^{3}$ Urology, Faculty of Medicine, Mansoura University \\ ${ }^{4}$ Medical Surgical Nursing, Faculty of Nursing, Benha University \\ E-mail of corresponding author: ahmedmena2003@yahoo.com
}

\begin{abstract}
:
Urinary diversion is associated with significant changes in urinary and sexual function, interpersonal relationships and psychosocial stress which ultimately affect patient's perceived quality of life (QoL).The aim of this study was to evaluate the effect of self-care learning package on the quality of life for patients undergoing urinary diversion Subjects and Methods: The study was carried out at urology unit of General Benha Hospital at Benha University and Urology and Nephrology Center of Mansoura University Hospitals. Sample included 100 patients whose undergoing urinary diversion from both sexes. The researcher used 3 tools in this study including, patient's assessment questionnaire, Interviewing questionnaire sheet, Functional Assessment of Cancer Therapy- Vanderbilt Cystectomy Index, (FACT-VCI). Results: the study results revealed that, highly statistically significant improvement in studied group about their total knowledge score, and total practice with subsequent improvement in total quality of life score for studied subjects with ileal loop conduit and orthotopic ileal neobladder after implementation of self-care learning package. Conclusion: Self care learning package have positive effect on quality of life for patients with different types of urinary diversion, and the mean score of knowledge, and practice improved significantly after application of self care learning package. Recommendation: The study recommended the application of guiding educational and cultural programme for patients with urinary diversion to improve their self-care for urinary diversion.
\end{abstract}

Keywords: Urinary diversion, Self-care learning package, Health related quality of life.

\section{Introduction:}

Urinary diversion is a provision of an alternate a path for urine to exit the body other than the ureters, bladder, urethra route; this can be accomplished by creating a pouch for collecting urine that then exits through a stoma, or by diverting the ureters to a stoma and allowing urine to free-flow through an opening in the abdomen (Craven, Hirnle, and Jensen, $2012 \&$ Ramont and Niedringhaus, 2008 and Timby and Smith, 2014).

The American Cancer Society's estimates for bladder cancer in the United States for 2014 are; about 74,690 new cases of bladder cancer diagnosed (about 56,390 in men and 18,300 in women), about 15,580 deaths from bladder cancer (about 11, 170 in men and 4,410 in women). In Egypt, carcinoma of the bladder is the main oncologic problem. At the National Cancer Institute (NCI), Cairo, urinary bladder cancer constitutes 30.3\% of all cancers, $40.6 \%$ of male cancers, and 14.3\% of female cancers (American Cancer Society, 2014).

Radical cystectomy followed by urinary diversion is regarded as the 'gold standard' treatment for carcinoma 
invading the bladder muscle without detectable hematogenous or lymphogenous metastases. This traumatic event is associated with significant changes in urinary and sexual function, interpersonal relationships and psychosocial stress which ultimately affect patient's perceived quality of life (QoL) (Guillotreau, Castel-Lacana Roumiguie, 2011).

Patients whose receive preoperative education end up choosing the method that is most suitable for them and are well prepared for the adjustment after surgery. It seems that patient education, careful evaluation of each patient's unique clinical and psychosocial situation and active patient participation in treatment decisions remain crucial to good postoperative quality of life (Singh, Yadav, Sinha and Gupta, 2013).

Patients facing radical cystectomy for high-risk bladder cancer have substantial fears about body image, sexuality and urinary function. These concerns not only involve potentially negative perceptions of their future health and functional wellbeing, but also encompass uncertainties about the practical impact of treatment and recovery on family members. These issues can greatly influence the choice of treatment and diversion, resulting in patient withdrawal from health decisions, limited treatment- seeking behavior and potential delays in treatment delivery (Lee and Latini, 2008).

All patients undergoing cystectomy were educated extensively by the surgeon as well as the uro-oncology nurse. The uro-oncology specialist nurses are involved in pre-operative teaching and postoperative care of the patients. They are also involved in the perioperative support and follow up. This includes stoma siting, pre-operative preparation and assessment of the optimum procedure (Philip, Manikandan, Venugopal, et al., 2009).

\section{Significance of the study:}

Nurses are critical in the transition from initial shock to acceptance and competent self-care for these people with different types of urinary diversion as they provide urostomy care and education and needed skills that focuses on full rehabilitation. The more nurses understand how this adjustment occurs, the more they can facilitate this process (Strode, 2009).

This study was provide patients undergoing urinary diversion with knowledge and skills which are of great importance in implementing their self care besides highlight the importance of patient's role in self-care activities which could have a direct influence on improving their quality of life. Also this study will help patients with different types of urinary diversion to decrease occurrence of complications for better and productive life with presence of stoma.

Aim of the study:

To evaluate the effectiveness of Self Care Learning Package on the Quality Of Life for Patient with Urinary Diversion through the following:

- Assessment of patient's knowledge and practice regarding urinary diversion (pre and post) application of self-care learning package.

- Developing and implement self -care learning package for patients with urinary diversion.

- Evaluate the effect of self-care learning package on quality of life for patients with different types of urinary diversion at the study sitting.

Hypothesis:

- The patient's knowledge and practice regarding urinary diversion will be increase post implementation of selfcare learning package than pre implementation of self-care learning package.

- Implementation of self-care learning package will improve quality of life 
for patients with different types of urinary diversion.

\section{Subjects and methods:}

\section{Research design:}

A quasi experimental design was utilized in this study.

\section{Variables:}

The independent variable was the designed self care learning package, while the dependent variables were patient' quality of life, and knowledge, practice related to self care for urinary diversion.

\section{Research Setting:}

This study was conducted in urological unit at Benha University Hospital, as well as in out patients clinics of Urology and Nephrology Center at El- Mansoura University Hospitals.

\section{Subjects:}

Purposive subject of (100) adult patients were recruited for the conduction of this study regardless to their gender, residence, occupation, or level of education. Subjects were recruited for the study with the following inclusion criteria, ability to participate in the educational programme, ability to manage the pouch and drainage apparatus. The exclusion criteria were having chronic diseases that interfere with their self-care activities as (cerebral stroke, paralysis, handicapped).

\section{Tools for Data Collection:}

Three tools were piloted and used by the researcher to collect data including:

Tool I: Patient's assessment Questionnaire, which was developed and used by the researcher, to collect necessary data about patients in this study, comprised of two parts:

A.Sociodemographic characteristics of the patients: as age, gender, marital status, educational level, residence, occupation, monthly income, family members, room's number, and smoking habit, etc....... It composed of (15) closed ended questions.

Tool II: self-care questionnaire:
To assess subjects' knowledge needs in form of multiple choice questions. It was divided into two major sections, patient' knowledge, Patient's practice observational checklist.

Tool III: Functional Assessment of Cancer Therapy- Vanderbilt Cystectomy Index, (FACT-VCI), that was adopted from Cookson, Dutta, Chang, et al, (2003), and developed to assess the quality of life for patients with radical cystectomy and urinary diversion as a method of treatment for cancer bladder.

\section{Pilot study:}

A pilot study was conducted on group 10 patients with urinary diversion in order to test the clarity and applicability of the study tools. Required modifications were done in the form of adding or omission of some questions. The time needed to fill in the questionnaire was about (45-50 minutes). Patients involved in the pilot study were excluded from the main study subjects.

\section{Procedures:}

Self-care learning package application comprised the following phases:

\section{A- Assessment Phase:}

This was the first phase in the program, where data were collected from patients and from their current medical records as baseline measures for their knowledge needs, and quality of life assessment. Using study tools I, II, III, which included; sociodemographic data, medical history, patient's knowledge, and practice, assessment for quality of life.

An exploratory visit was done to urology units and urological outpatients' clinic at both setting of the study in order to estimate the rate of admission and suitable time for collecting data.

Besides, personal communication was done with nurses and physician to explain the purpose of the study and gain their best possible cooperation. The Patients who met the study criteria were included in the 
study after explaining the nature and purpose of the study and obtaining their consents.

- All the questionnaires were distributed to all patients to assess patients' educational needs and obtain baseline data about their quality of life.

\section{B-Planning Phase (program development):}

General and specific objectives of proposed self care learning package for urinary diversion were designed based on predetermined subjects; preprogram assessment (baseline measures), relevant literature, and opinions of the medical and nursing experts. This intervention was revised and modified based on the experts' comments, in order to be implemented using various methods including a booklet contained major headlines of the self-care learning package about urinary diversion, which was designed by researcher, and written in a very simple Arabic language as well as supplemented by photos and illustrations, entitled "Urinary Diversion".

The objectives and content of the urinary diversion and urostomy management guidelines were established based on review of related literatures (American Cancer Society, 2014; Black, and Hawks, 2009; Smeltzer, et al., 2010; Lewis et al., 2014), as well as patients' educational needs obtained from the collected data. It was designed in an Arabic language. Each part of the booklet was pertaining to different aspects of Urinary diversion and how to manage them.

The first aspect (theoretical part) included; knowledge about urinary diversion which were cover; types, indication, preoperative care, postoperative care, complications both early and late complications, adaptation for life with urinary diversion both physically, psychologically, socially, and financially. The second aspect (practical part) included the procedures for care of urostomy including pouching system changing of pouch, empty of pouch, selfcatheterization for urostomy, irrigation of urostomy. how to evacuate the neobladder, exercises to strength the pelvic floor muscles, ongoing intermittent selfcatheterization, multiple measures for mucus management, including irrigation, strategies that reduce the volume of mucus production and mucus viscosity, how to deal with day and night incontinence. Media was prepared by the researchers, including the guidelines handout and audiovisual materials as CD.

Content validity of the guidelines was tested through experts' opinions. Those experts included by seven professions and experts, three assistant professor of medical surgical nursing, two lecturer of medical- surgical nursing in the faculty of nursing, at Mansoura University and Benha University. Two professor of urology in the faculty of medicine, at Mansoura University.

Implementation phase: During implementation phase, implementation of the self care learning package was done through group teaching. The group teaching compromised of 3 patients. Matching was done for subjects within each group in relation to type of urinary diversion, age and educational level. At the end of the program, the researcher was take feedback from subjects to assess patient knowledge and quality of life after 3 month's interval. The researcher thanks them for cooperative with him, and asks them about their opinion about the program and their benefits from the program. Self-care learning package explained through modified lectures, discussions, demonstration and redemonstration based on his needs and level of understanding for 10 successive sessions. An instructional media was used. Each session took approximately 20-30 minutes. The researchers telephone number were given to studied patients and 
patients' telephone number were taken to ensure contact and meeting them during follow up visits in outpatients clinics to complete data collection during follow up period.

Evaluation phase: Postimplementation of the self care learning package, assessment was done using the same pretest tools except patients' assessment and clinical data sheet. Comparison between the collected data before and after the implementation of self care learning package was done to determine the effectiveness of this programme in improvement of quality of life for patients with urinary diversion.

\section{Administrative design:}

An official permission was obtained from the manager of Urology Unit at Benha University Hospital, and another one was obtained from the manager of Urology and Nephrology Center at ElMansoura University Hospitals. A letter was issued to them from dean of the Faculty of Nursing, Benha University explaining the aim of the study to obtain the permission for data collection.

\section{Ethical consideration:}

Ethical approval was obtained from the Scientific Ethical Committee of Benha University. The purpose of the study was explained to the patients and oral consent was obtained from them to participate in this study. They were given an opportunity to withdraw from the study without given a reason and they were assured that anonymity and confidentiality of information was protected. Ethics, values, culture, and beliefs were respected.

\section{Statistical analysis:}

The collected data were tabulated and statistically analyzed using an IBM computer and the statistical package for social science (SPSS) advanced statistics, version 14 (SPSS Inc., Chicago, IL). Numerical data were expressed as mean and standard deviation. Qualitative data were expressed as frequency and percentage. For quantitative data, comparison between two groups was done using either student t-test Fisher exact test, McNemar's test for equality of means and coefficient relation to detect the relations between the variables. Also cronbach's alpha test was used to test the reliability of the tool. 


\section{Results:}

Table (1): Percentage Distribution of Studied $(\mathrm{N}=100)$ regarding their Demographic characteristics

\begin{tabular}{|c|c|c|}
\hline \multirow{2}{*}{ Demographic Characteristic } & \multicolumn{2}{|c|}{ Studied subjects $(\mathrm{N}=100)$} \\
\hline & No & $\%$ \\
\hline \multicolumn{3}{|l|}{ Age: } \\
\hline$<45$ & 15 & 15.0 \\
\hline $45-$ & 16 & 16.0 \\
\hline $50-$ & 12 & 12.0 \\
\hline $55-$ & 10 & 10.0 \\
\hline $60-$ & 24 & 24.0 \\
\hline \multirow{2}{*}{$\begin{array}{l}65+ \\
\text { Mean } \pm \text { SD }\end{array}$} & 23 & 23.0 \\
\hline & \multicolumn{2}{|c|}{$55.95 \pm 9.55$} \\
\hline \multicolumn{3}{|l|}{ Education level: } \\
\hline Illiterate. & 41 & 41.0 \\
\hline Read and write. & 35 & 35.0 \\
\hline Primary and secondary. & 14 & 14.0 \\
\hline University. & 10 & 10.0 \\
\hline \multicolumn{3}{|l|}{ Income: } \\
\hline Sufficient. & 17 & 17.0 \\
\hline Sufficient and save. & 1 & 1.0 \\
\hline Not enough. & 81 & 81.0 \\
\hline Sometimes borrow. & 0 & 0.0 \\
\hline Always borrow. & 1 & 1.0 \\
\hline \multicolumn{3}{|l|}{ Smoking: } \\
\hline Smoking. & 43 & 43.0 \\
\hline Not smoking. & 56 & 56.0 \\
\hline Stop smoking. & 1 & 1.0 \\
\hline
\end{tabular}

The characteristics of the study sample are described in table (1): illustrates more than two third $(47 \%)$ of studied subjects were in age group from 55 years to 65 years, with mean $56.6 \pm 10.5$, and $(41.0 \%)$ of them were illiterate, respectively.

Table (2): Percentage Distribution of Studied Subjects with Ileal Loop Conduit $(\mathrm{N}=50)$ and Ileal Neobladder $(\mathrm{N}=50)$ regarding to Their Total Knowledge Score pre and post Application of Self Care Learning Package

\begin{tabular}{|l|l|c|c|c|c|}
\hline \multicolumn{2}{|c|}{ Total knowledge Score } & $\begin{array}{c}\text { Ileal loop Conduit } \\
\text { ( N= 50) }\end{array}$ & \multicolumn{2}{c|}{$\begin{array}{c}\text { Ileal Neobladder } \\
\text { ( N= 50) }\end{array}$} \\
\cline { 3 - 6 } \multicolumn{2}{|c|}{} & No & $\%$ & No & $\%$ \\
\hline $\begin{array}{l}\text { Pre implementation of } \\
\text { SLP }\end{array}$ & Unsatisfactory & 50 & 100.0 & 50 & 100.0 \\
\hline $\begin{array}{l}\text { post implementation of } \\
\text { SLP }\end{array}$ & Unsatisfactory & 6 & 12.0 & 15 & 30.0 \\
\cline { 2 - 6 } & Satisfactory & 44 & 88.0 & 35 & 70.0 \\
\hline McNemar's test & \multicolumn{3}{|c|}{42} & \multicolumn{2}{c|}{33} \\
\hline p value & \multicolumn{3}{c|}{$<0.001 * *$} & \multicolumn{2}{c|}{ SLP; Self care Learning Package. } \\
\hline
\end{tabular}


Table (2): shows the levels of knowledge of the studied subjects pre and post implementation of self-care learning package. It was showed that there is highly statistically improvement in total mean score of knowledge post implementation of self-care learning package when comparing with pre implementation of self-care learning package, for studied subjects with ileal loop conduit and ileal neobladder at $\left(\mathrm{p} \leq 0.001^{* *}\right)$.

Table (3): Percentage Distribution of Studied Subjects with Ileal Loop Conduit $(\mathrm{N}=50)$ regarding to Their Practice pre and post Implementation of Self Care Learning Package

\begin{tabular}{|l|c|c|c|c|c|c|}
\hline \multirow{2}{*}{ Item } & \multicolumn{2}{|c|}{$\begin{array}{c}\text { Practice } \\
\text { Pre SLM }\end{array}$} & \multicolumn{2}{c|}{$\begin{array}{c}\text { Practice } \\
\text { Post SLM }\end{array}$} & \multirow{2}{*}{ McNemar's } & \multirow{2}{*}{ P Value } \\
\cline { 2 - 7 } & No & $\%$ & N & $\%$ & & \\
\hline $\begin{array}{l}\text { Urostomy Care: } \\
\text { Qualified }\end{array}$ & 0 & 0.0 & 27 & 54.0 & 25.03 & $<0.001 *$ \\
Unqualified & 50 & 100.0 & 23 & 46.0 & & $*$ \\
\hline $\begin{array}{l}\text { Self-Catheterization } \\
\text { for Urostomy: }\end{array}$ & 0 & 0.0 & 49 & 98.0 & & \\
$\begin{array}{l}\text { Qualified } \\
\text { Unqualified }\end{array}$ & 50 & 100.0 & 1 & 2.0 & 47.01 & $<0.001 *$ \\
& & & & & & $*$ \\
\hline $\begin{array}{l}\text { Urostomy Irrigation: } \\
\text { Qualified }\end{array}$ & 0 & 0.0 & 0 & 0.0 & & - \\
\hline Unqualified & 50 & 100.0 & 50 & 100.0 & - & \\
\hline
\end{tabular}

(**) Highly statistically significant $<0.001 \quad$ SLP; Self care Learning Package.

Table (3) reveals that, there is statistically significant improvement for studied subjects with ileal loop conduit regarding their urostomy care, and self -catheterization, post implementation of self-care learning package at $\left(\mathrm{p} \leq 0.001^{* *}\right)$, while there is no statistically significant improvement for studied subjects with ileal loop conduit regarding their practice about urostomy irrigation.

Table (4): Percentage Distribution of Studied Subjects with Ileal Loop Conduit $(\mathrm{N}=50)$ and Ileal Neobladder $(\mathrm{N}=50)$ regarding to Their Total practice Score pre and post Application of Self Care Learning Package

\begin{tabular}{|l|l|c|c|c|c|}
\hline \multirow{2}{*}{\multicolumn{2}{|c|}{ Total practice score }} & \multicolumn{2}{c|}{$\begin{array}{c}\text { Ileal loop Conduit } \\
\text { ( N= 50) }\end{array}$} & \multicolumn{2}{c|}{$\begin{array}{c}\text { Ileal Neobladder } \\
\text { (N= 50) }\end{array}$} \\
\cline { 3 - 6 } \multicolumn{2}{|c|}{} & No & \% & No & \% \\
\hline \multirow{2}{*}{ pre SLP } & Qualified & 50 & 100.0 & 50 & 100.0 \\
\hline \multirow{2}{*}{ post SLP } & Unqualified & 21 & 42.0 & 5 & 10.0 \\
\cline { 2 - 6 } & Qualified & 29 & 58.0 & 45 & 90.0 \\
\hline \multicolumn{2}{|c|}{ McNemar's test } & \multicolumn{3}{|c|}{43} \\
\hline p value & \multicolumn{2}{|c|}{$<0.001 * *$} & \multicolumn{2}{c|}{$<0.001 * *$} \\
\hline
\end{tabular}

(**) Highly statistically significant $<0.001 \quad$ SLP; Self care Learning Package.

Table (4): shows that there is highly statistically significant improvement in each group about their total practice score post implementation of self-care learning package at $(\mathrm{p} \leq 0.001 * *)$. 
Table (5): Mean Score, Standard Deviation and Test of Significance of Quality of Life for The Studied Subjects with Ileal Loop Conduit by Using FACT-VCI Questionnaire pre and post Application of Self Care Learning Package:

\begin{tabular}{|c|c|c|c|c|c|}
\hline \multirow{2}{*}{$\begin{array}{l}\text { Quality Of Life's } \\
\text { Domains }\end{array}$} & \multicolumn{5}{|c|}{$\begin{array}{l}\text { Ileal Loop Conduit } \\
(N=50)\end{array}$} \\
\hline & $\operatorname{Mean} \pm \mathbf{S D}$ & Mean & SD. & $\begin{array}{c}\text { Paired } t \\
\text { test }\end{array}$ & $P$ value \\
\hline $\begin{array}{l}\text { Physical Well Being: } \\
\text { GP pre SLP. } \\
\text { GP follow up SLP. }\end{array}$ & $\begin{array}{c}63.6 \pm 20.11 \\
77.29 \pm 11.47\end{array}$ & 13.69 & 15.32 & 6.31 & $0.00 *$ \\
\hline $\begin{array}{l}\text { Social And Family Well } \\
\text { Being: } \\
\text { GS pre SLP. } \\
\text { GS follow up SLP. }\end{array}$ & $\begin{array}{l}75.55 \pm 18.71 \\
82.02 \pm 12.79 \\
\end{array}$ & 6.46 & 9.36 & 4.88 & $0.00 *$ \\
\hline $\begin{array}{l}\text { Emotional Well Being: } \\
\text { GE pre SLP. } \\
\text { GE follow up SLP. }\end{array}$ & $\begin{array}{l}61.08 \pm 20.54 \\
77.42 \pm 12.60\end{array}$ & 16.33 & 15.56 & 7.42 & $0.00 *$ \\
\hline $\begin{array}{l}\text { Functional Well Being: } \\
\text { GF pre SLP. } \\
\text { GF follow up SLP. }\end{array}$ & $\begin{array}{l}47.64 \pm 18.45 \\
67.71 \pm 12.50 \\
\end{array}$ & 20.07 & 14.55 & 9.7 & $0.00 *$ \\
\hline $\begin{array}{l}\text { Additional Concerns: } \\
\text { BICS pre SLP. } \\
\text { BICS follow up SLP. }\end{array}$ & $\begin{array}{l}71.13 \pm 7.27 \\
71.13 \pm 7.27\end{array}$ & 0.00 & 0.00 & - & - \\
\hline $\begin{array}{l}\text { Total FACT-VCI: } \\
\text { FACT-VCI pre SLP. } \\
\text { FACT-VCI follow up } \\
\text { SLP. }\end{array}$ & $\begin{array}{c}63.92 \pm 12.95 \\
74.61 \pm 7.39\end{array}$ & 10.6 & 7.5 & 10.03 & $0.00 *$ \\
\hline
\end{tabular}

GP, physical well being; GS, social well being; GE, emotional well being; GF, functional well being; BICS, bladder cancer subscale; FACT-VCI, functional assessment of cancer therapy -Vanderbilt cystectomy index; SD, Slandered Deviation.

(**) Highly statistically significant $<0.001$ Package.

SLP; Self care Learning

Table (5) reveals that there is highly statistically significance improvement in studied subjects with ileal loop conduit regarding their mean score of quality of life at ( $\mathrm{p} \leq$ $\left.0.05^{*}\right)$, except for additional concerns score at follow up for implementation of self-care learning package. 
Table (6): Mean Score, Standard Deviation and Test of Significance of Quality of Life for The Studied Subjects with Ileal Neobladder by Using FACT-VCI Questionnaire pre and post Application of Self Care Learning Package:

\begin{tabular}{|c|c|c|c|c|c|}
\hline \multirow[b]{2}{*}{ Quality Of Life's Domains } & \multicolumn{5}{|c|}{ In Ileal- Neobladder $(\mathrm{N}=50)$} \\
\hline & Mean \pm SD. & Mean & SD. & $\begin{array}{c}\text { Paired } t \\
\text { test }\end{array}$ & $\begin{array}{c}\mathbf{P} \\
\text { value }\end{array}$ \\
\hline $\begin{array}{l}\text { Physical Well Being: } \\
\text { GP pre SLP. } \\
\text { GP follow up SLP. }\end{array}$ & $\begin{array}{l}68.21 \pm 17.75 \\
81.43 \pm 12.39\end{array}$ & 13.21 & 11.68 & 7.99 & $0.00 *$ \\
\hline $\begin{array}{l}\text { Social And Family Well } \\
\text { Being: } \\
\text { GS pre SLP. } \\
\text { GS follow up SLP }\end{array}$ & $\begin{array}{l}87.13 \pm 17.87 \\
87.13 \pm 17.87\end{array}$ & 0.00 & 0.00 & - & - \\
\hline $\begin{array}{l}\text { Emotional Well Being: } \\
\text { GE pre SLP. } \\
\text { GE follows up SLP. }\end{array}$ & $\begin{array}{l}63.08 \pm 18.97 \\
76.42 \pm 14.47\end{array}$ & 13.33 & 10.17 & 9.26 & $0.00 *$ \\
\hline $\begin{array}{l}\text { Functional Well Being: } \\
\text { GF pre SLP. } \\
\text { GF follow up SLP. }\end{array}$ & $\begin{array}{l}45.71 \pm 19.45 \\
67.29 \pm 14.24\end{array}$ & 21.5 & 15.8 & 9.6 & $0.00 *$ \\
\hline $\begin{array}{l}\text { Additional Concerns: } \\
\text { BICS pre SLP. } \\
\text { BICS Post SLP }\end{array}$ & $\begin{array}{l}72.37 \pm 8.57 \\
72.37 \pm 8.57\end{array}$ & 0.00 & 0.00 & - & - \\
\hline $\begin{array}{l}\text { Total FACT-VCI: } \\
\text { FACT-VCI pre SLP. } \\
\text { FACT-VCI follows up SLP. }\end{array}$ & $\begin{array}{c}67.01 \pm 12.01 \\
76.34 \pm 7.85\end{array}$ & 9.33 & 6.06 & 10.8 & $0.00 *$ \\
\hline
\end{tabular}

GP, physical well being; GS, social well being; GE, emotional well being; GF, functional well being; BICS, bladder cancer subscale; FACT-VCI, functional assessment of cancer therapy-Vanderbilt cystectomy index; SD, Slandered Deviation.

$(* *)$ Highly statistically significant $<0.001 \quad$ SLP; Self care Learning Package.

Table (6) reveals that there is highly statistically significance improvement in studied subjects with ileal neobladder regarding their mean score of quality of life at $(\mathrm{p} \leq$ $0.05^{*}$ ), except for social and family well-being, additional concerns score at follow up for implementation of self-care learning package

\section{Discussion:}

With the proliferation of urinary diversion options for bladder cancer that have comparable cancer control and complication rates, quality of life becomes an important factor to consider. Healthrelated quality of life (HRQOL) refers to the physical, psychological, and social domains of health that are influenced by a person's experiences, beliefs, expectations, and perceptions (Lagrange, BascoulMollevi, Geoffrois, et al. 2011).

Regarding characteristics of the patients under study, it was found that less 
than half (47\%) of studied subjects were in age group from 55 years to 65 years, with mean 56.6 \pm 10.5. this finding is in agreement with the finding of El-Sayed, El-Azab, and El-Gammal, (2013), in their study about; Quality of Life in Bladder Cancer Patients Treated with Radical Cystectomy and Orthotopic Bladder Reconstruction versus Bladder Preservation Protocol, who found that the median age at the time of study enrollment was 55 years (range: 36-75). Most of studied subjects were male. This finding is in agreement with Tyritzis, Hosseini, Collins, et al., (2013), in study about; Oncologic, Functional, and Complications Outcomes of Robot-assisted Radical Cystectomy with Totally Intracorporeal Neobladder Diversion; who found that a total of 62 of 70 patients $(88.6 \%)$ were men; 2 of 8 female patients $(25 \%)$ underwent an organ-sparing procedure and urinary diversion.

It was found that more than two third of the studied subjects were illiterate. This finding is in accordance with Stenzl, Sherif, and Kuczyk, (2010) who found that the majority of their subjects were illiterate.

Concerning to income, the finding of the present study showed that most of studied subjects were had not enough income. This finding is congruent with Erber, Schrader, Miller, et al., (2012), who found that financial difficulty scores were significantly lower in the orthotopic ileal neobladder group than the ileal loop conduit group at 6-, 12- and 18-month follow-ups.

The goal of all patient education is to improve quality of life and clinical outcomes by teaching appropriate self management skill. Regarding patients' level of knowledge pre and post self care learning package implementation, the study revealed presence of highly statistically significant improvement in all items of knowledge. This finding is in agreement with Altuntas, Kement, Gezen,

Et Al., (2012), who stated that the comparison of pre-education and posteducation SF-36 scores revealed a statistically significant improvement in all 8 -scale profiles. In addition, in their opinion, group educations may be beneficial for stoma patients, and stoma therapy units may consider organizing similar activities. As well as, this finding is in agreement with Autorino, Quarto, Di Lorenzo, et al., (2009); who found that good counseling pre-operatively and establishing patient's expectations prior helps with the general acceptance of either procedure. They also recommended that meticulous counseling of patients and their relatives should be done prior to the operation and a further shorter session pre-theatre. This will ensure that patients understand what to expect and how to deal with any complication, or sequel related to the procedure. Additionally, this finding is in agreement with Stenzl, Cowan, Santis, et al., (2011), who pointed that Patients undergoing any type of urinary diversion have to be motivated to learn to cope with their diversion and to develop the manual dexterity required.

Regarding patients' level of practice pre and post implementation of self care learning package, the present study revealed that there is highly statistically significant improvement in each group about their total practice score post implementation of self-care learning package at $\left(\mathrm{p} \leq 0.001^{* *}\right)$. This result is consistent with Ries et al. (2007) who mentioned that, coping with a chronic condition involves skills training, learning to manage a number of symptoms, and consciously assessing and making lifestyle changes. Experience has shown that those who develop a management plan with their health care team and follow it can live better with urinary diversion, and improve their quality of life. 
The present study reveals that there is highly statistically significance improvement in studied subjects with ileal loop conduit regarding their mean score of quality of life at $\left(p \leq 0.05^{*}\right)$, except for additional concerns score at follow up for implementation of self-care learning package. As well as, there is highly statistically significance improvement in studied subjects with ileal neobladder regarding their mean score of quality of life at $\left(\mathrm{p} \leq 0.05^{*}\right)$, except for social and family well-being, additional concerns score at follow up for implementation of self-care learning package. This finding is in congruent with Kassouf, Hautmann, Bochner, et al., (2010), who pointed that when comparing ileal conduits with continent cutaneous diversions, they have shown that patients are satisfied regardless of the type of diversion and adapt well biopsychosocially as long as an adequate and realistic preoperative education is instituted about their type of diversion, in which preoperative patient information, patient selection, surgical techniques, and careful postoperative follow-up are the cornerstones to achieve good long-term results after urinary diversion surgery. As well as, Hautmann, Abol-Enein, Davidsson, et al., (2013)pointed that significant improvement in every area studied, including travel, sports, dressing issues, skin irritation, odor, and sexual issues was reported after application of enterostomal therapy and education. Moreover, Montie, and Gilbert ( 2010) revealed that although postoperative HRQOL outcomes are an important component of counseling prior to urinary diversion procedures, the decision-making process concerning the appropriate type of diversion involves patient education, participation, and in-depth discussion of patient preferences given the preferencesensitive nature of choosing between a conduit and continent diversion.

\section{Conclusion:}

The current study concluded that, self care learning package has positive effect on patients' level of knowledge and practices regarding management of urinary diversion and urostomy. Also, quality of life had been improved in patients with urinary diversion who received self care learning package. These means all the study hypotheses had been proved.

\section{Recommendations:}

According to results of the current study, the following suggestions are recommended:

(1) Periodic health teaching programme for patients with urinary diversion and their families in outpatients' clinics with simplified printed guidelines through leaflets, brochures or booklets, and should be held to update the knowledge and practices needed for patients with different types of urinary diversion about selfmanagement.

(2) Prospective follow up studies are needed to develop and refine interventions to improve self-care management for patients with urinary diversion.

(3) Further research must focus on selfmanagement for urostomy and orthotopic urinary diversion.

\section{References:}

1- Altuntas, Y., E., Kement, M., Gezen, C., Eke, H., H., Aydin, H., Sahin, F., Okkabaz, N., and Oncel, M., (2012): The role of group education on quality of life in patients with a stoma .European Journal of Cancer Care, Volume 21, Issue 6, pages 776781. Accessed at November 2012.

2-American Cancer Society, (2014): Cancer Facts \& Figures .Atlanta, Ga: American Cancer Society.

3-Autorino, R., Quarto, G., Di Lorenzo, G., De Sio, M., Perdona, S., 
Giannarini, G., et al. (2009): Health related quality of life after radical cystectomy: comparison of ileal conduit to continent orthotopic neobladder. Eur J SurgOncol.; 35: 858-864. Available at: www.sciencedirect.com .journal home page: http:// www.europeanurology.com.

4- Black, J., M., and Hawks, J., H., (2009): Medical- Surgical Nursing:Clinical Management for Positive Outcome, 8th ed., St.LousSaunders Elsevier comp., pp 740-748.

5- Cookson, M., S., Dutta, S., C., Chang, S., S., Clark, T., Smit, JA., Jr., and Wells, N., (2003): Health related quality of life in patients treated with radical cystectomy and urinary diversion for urothelial carcinoma of the bladder: development and validation of a new disease specific questionnaire. J Urol, 170:1926-1930.

6- Craven, R.F., Hirnle, C.J., and Jensen, S., (2012): Fundamental of Nursing Human and Function, $7^{\text {th }}$ ed., Philadelphia Lippincott Williams \& Wilkins, pp 1078.

7- El-Sayed, M., I., El-Azab, A., S., and El-Gammal, M., A., (2013): Quality of Life in Bladder Cancer Patients Treated with Radical Cystectomy and Orthotopic Bladder Reconstruction versus Bladder Preservation Protocol. J Cancer Sci Ther 5(5):190-193. doi:10.4172/1948-5956.1000205.

ISSN: 1948-5956 JCST, an open access journal.

8- Erber, B., Schrader, M., Miller, K., Schostak, M., Baumunk, D.,
Lingnau,A.,

Schrader,A.,J., and Jentzmik,F., (2012): Morbidity and quality of life in bladder cancer patients following cystectomy and urinary diversion: A single-institution comparison of ileal conduit versus orthotopic neobladder. ISRN Urol: 342796.Published online Feb 6, 2012.doi: 10.5402/2012/342796. ISRN Urol: 342796. doi: 10.5402/2012/342796.

9- Guillotreau, J., Castel-Lacana E., Roumiguie, M., Bordier, B., Doumerc, N., De Boissezon, X., Malavaud, B., Marque, P., Rischmann, P., and Gamé, X., (2011): Prospective Study of the Impact on Quality of Life of Cystectomy with Ileal Conduit Urinary Diversion for Neurogenic Bladder Dysfunction. Neurourology and Urodynamics; 30:1503-1506.doi: 10.1002/nau.21121. Epub 2011 Jun 14.

10-Hautmann, R., E., Abol-Enein, H., Davidsson, T., Gudjonsson ,S., Hautmann, S.,H., Holm, H., V., Lee, C.,T., Liedberg, F., Madersbacher, S., Manoharan, M., Mansson, W., Mills, R.,D., Penson, D., F., Skinner, E., C., et al. (2013): ICUD EAU International Consultation on Bladder Cancer 2012: Urinary Diversion. Eur Urol; 63:67 80. Available at: HTTP:// www.sciencedirect.com . Journal homepage:

www.europeanurology.com. doi.org/10.1016/j.eururo.2012.08.050

11-Kassouf, W., Hautmann, R., E., Bochner, B., H., Lerner, S., P., Colombo, R., Zlotta, A., Studer, U., E., (2010): A Critical Analysis of 
Orthotopic Bladder Substitutes in Adult Patients with Bladder Cancer: Is There a Perfect Solution? European Urology 58(3):374-83. Available at: http://www.sciencedirect.com. Journal homepage:

www.europeanurology.com.

12-Lagrange, J., L., Bascoul-Mollevi, C., Geoffrois, L., Beckendorf, V., Ferrero, J.,M., Joly, F., Allouache, N., Bachaud, J.,M., Chevreau, C., Kramar, A., Chauvet, B., (2011): Quality of life assessment after concurrent chemoradiation for invasive bladder cancer: results of a multicenter prospective study (GETUG 97-015). International Journal of Radiation Oncology Biology Physics; 79(1):172-178.doi:

10.1016/j.ijrobp.2009.10.038. Epub 2010 Apr 10.

13-Lee, C., T., and Latini, D., M., (2008): Urinary diversion: evidencebased outcomes assessment and integration into patient decisionmaking. BJU, International 102: 1326-1333. Doi:10.1111/J.1464410x.2008.07978.

14-Lewis, S. L., Heitkemper, M.M., Dirksen, S. R., O'Brien, P.G., and Bucher L., Harding, M., (2014): Medical- Surgical Nursing: Assessment and Management of Clinical Problems, $9^{\text {th }}$ ed., St. Lous Mosby Elsevier Company, pp 10641075.

15-Montie, and Gilbert (2010): Incontinent or continent urinary diversion: how to make the right choice. Curr, opin urol. Sep;
20(5):421-5. doi:

10.1097/MOU.0b013e32833c9661

16-Philip, J., Manikandan, R., Venugopa, S., Desouza, J., Javlé, P., M., (2009): Orthotopic neobladder versus ileal conduit urinary diversion after cystectomy - a quality-of-life based comparison. Ann R Coll Surg Engl; 91: 565-569, doi 10.1308/003588409X432293.

17-Ramont, R.P., and Niedringhaus, D.M., (2008): Fundamental Nursing Care, $2^{\text {nd }}$ ed., Pearson Prentice Hall Company, p582.

18-Ries, A., Bauldoff, G., Carlin, B., Casaburi, R., Emery, C., Mahler, D., et al. (2007): Pulmonary Rehabilitation: Joint ACCP/AACVPR Evidence Based Clinical Practice Guidelines. Chest. 2007; 131: 4S$42 \mathrm{~S}$.

19-Singh, V., Yadav, R., Sinha, R., J., and Gupta, D., K., (2014): Prospective comparison of quality-oflife outcomes between ileal conduit urinary diversion and orthotopic neobladder reconstruction after radical cystectomy: a statistical model. BJU Int; 113: 726-32 doi:10.1111/bju.12440

20-Smeltzer, S., C., Bare, B., G., Hinkle, J., L., and Cheever, K., H., (2010): Brunner \& Sauddarth's Text Book of Medical Surgical Nursing. $12^{\text {th }}$ ed., volume (1). Philadelphia Lippincott, William \& wikins. New York. London, Buenos Aires, Hong Kong. Pp: 11381-11388.

21-Stenzl, A., Cowan, N., C., De Santis, M., Kuczyk, M., A., Merseburger, A., Ribal, M., J., Sherif, A., Witjes, J., A., (2011): Treatment of Muscle- 
Mona Mohammed Ibrahim et. al.

invasive and Metastatic Bladder

Cancer: Update of the EAU

Guidelines. Eur Urol 3849; No. of

Pages 10.Available at: http://

www.sciencedirect.com. Journal

homepage: http://

www.europeanurology.com.

22-Stenzl, A., Sherif, H., and Kuczyk, M., (2010): Radical cystectomy with orthotopic neobladder for invasive bladder cancer: a critical analysis of long term oncological, functional and quality of life results. Int Braz J Urol, 36(5):537-47.

23-Timby, B.K., and Smith, N.E. (2014): Introductory Medical- Surgical Nursing, $11^{\text {th }}$ ed., Philadelphia Lippincott, William \& wikins, pp1021-1030.
24-Tyritzis, S., I., Hosseini ,A., Collins , J., Nyberg, T., Martin N. Jonsson , M., N., Laurin,O., Khazaeli , D., Adding , C., Martin Schumacher , M., Peter Wiklund, N., P., ( 2013): Oncologic, Functional, and Complications Outcomes of Robotassisted Radical Cystectomy with Totally Intracorporeal Neobladder Diversion. European Urology 6 4, 73 4 - $\begin{aligned} & 7 \\ & 4\end{aligned}$ 1. Available at: http// www.sciencedirect.com. Journal homepage:

www.europeanurology.com. 